\title{
KEMERDEKAAN PERS PADA ORDE REFORMASI
}

\author{
Oleh : \\ Muhammad Syahnan Harahap \\ Dosen Tetap Fakultas Hukum Universitas Dirgantara Marsekal Suryadarma Jakarta, \\ Email : msyahnanh@gmail.com
}

\begin{abstract}
The freedom of the press in the reform remains based on article 28 of the 1945 Constitution. Just as the old order and the new order. The demand of the reform order is independence or freedom. The upholding of human rights in this case is freedom to voice opinions or feelings through the press media. Still its implementation depends on the political system and legislation that develops in the country including those concerning the responsibility of the press it self.
\end{abstract}

Key words : independence, pers, order of reform

\section{PENDAHULUAN}

\section{A. LATAR BELAKANG}

Dengan runtuhnya kekuasaan orde baru tanggal 21 Mei 1998, muncul orde reformasi yang menghendaki adanya perubahan terhadap semua sektor pembangunan, seperti pembangunan di bidang politik, ekonomi, sosial dan kultural. Reformasi telah menghasilkan buahnya sendiri. Ciri yang menonjol dari reformasi itu adalah adanya kemerdekaan dan kebebasaan.

Salah satu buah manis dari orde reformasi itu adalah kemerdekaan pers. Pers dapat menikmati kemerdekaan itu. Tidak ada tembok pembatas yang menghalanginya dalam membuat dan menyebarkan informasi kepada masyarakat. Pers berkembang dengan pesat dan bahkan cenderung liar. Negara berada dalam dunia maya, yang seolah-olah sudah tidak ada lagi batas- batas negara. (Borderlees), apa yang terjadi di negara lain dapat kita saksikan di negara kita. Dunia ini ibarat kampung besar (Global Vilage).

Selanjutnya kita dapat menyaksikan dalam melakukan tugastugas jurnalistiknya para wartawan cenderung mengabaikan kaidah-kaidah hukum dan etika jurnalistik. Sehingga tindakannya sering kali berwujud pada pencideraannya narasumber atau subyek hukum berita. Selain itu dapat terjadi karena kurang kehati-hatian dalam melaksanakan tugas jurnalistiknya dan /atau dapat juga karena faktor ekonomi atau bisnis. Padahal yang kita ketahui bahwa pers itu tidak semata-mata mempunyai fungsi bisnis akan tetapi juga mempunyai fungsi sosial politik.

Kita dapat menyadari terjadinya eforia yang terlalu berlebihan itu karena adanya pencabutan peraturan menteri penerangan Nomor 1 Tahun 1984 tentang Surat Izin Penerbitan Pers 
(SIUPP) dicabut. Departemen penerangan dibubarkan, amandemen UUD 1945, perubahan terhadap UU No. 21 Tahun 1982 menjadi UU No. 40 Tahun 1999 tentang Pokok-Pokok Pers. Bahkan juga lahir UU No. 39 Tahun 1999 tentang Undang-Undang Hak Asasi Manusia.

Kemudian pasal-pasal karet dalam KUHP pada masa Yusril Iza Mahendra sebagai Menteri Kehakiman di cabut, yang pada zamannya dianggap sebagai momok bagi kemerdekaan pers. Eforia itu menjadi terbelenggu lagi dengan keluarnya UU No. 11 Tahun 2008 tentang UndangUndang Informasi Transaksi dan Elektronik. Sampai saat ini pers seolaholah sudah menjadi corong pemerintah.

Padahal pasal 28 UUD 1945 menentukan bahwa :

"kemerdekaan berserikat dan berkumpul, mengeluarkan pikiran dengan lisan dan tulisan dan sebagainya ditetapkan dengan Undang-Undang"

Dalam penjelasan pasal 28 UUD 1945, walaupun sudah tidak berlaku dengan amandemen UUD 1945, akan tetapi dari segi akademis dalam kerangka membentuk wacana berfikir konstruktif masih diperlukan dan menentukan bahwa :

"pasal-pasal baik yang mengenai warga negara maupun seluruh penduduk memuat hasrat bangsa Indonesia untuk membangunkan negara yang demokratis dan hendak melaksanakan keadilan sosial dan peri kemanusiaan".

Apabila bunyi pasal 28 itu dan penjelasan UUD 1945 secara khusus ditarik kedalam kemerdekaan pers berarti kita hendak membangunkan kemerdekaan pers yang demokratis, berperikemanusiaan dan berkeadilan sosial.
Hasrat itu juga senada dan sebangun dengan pasal 2 UU No. 21 Tahun 1982 tentang Undang-Undang Pokok Pers yang menentukan bahwa :

"kemerdekaan pers adalah salah satu wujud kedaulatan rakyat yang berazaskan demokrasi, keadilan sosial dan supremasi hukum, dan dalam pasal 4 ayat 1 dari Undang-Undang itu menyebutkan juga bahwa : kemerdekaan pers dijamin sebagai hak asasi warga negara".

Berkenaan dengan pentingnya kemerdekaan pers Mark Twain mengatakan, hanya ada dua yang dapat menjadikan dunia ini terang; yang pertama matahari dilangit dan yang kedua pers di dunia ${ }^{4}$. Hal itu menunjukkan pada kita betapa pentingnya fungsi dan peranan pers dalam kehidupan masyarakat. Dapat diketahui yang menjadi fungsi pers dalam kehidupan masyarakat adalah sebagai media informasi, pendidikan, kritik, koreksi, barometer atau alat kontrol dan sebagai hiburan ${ }^{5}$. Fungsi pers itu akan lebih fungsional lagi apabila didekati dari nilai etis, artinya layak atau tidaknya suatu berita itu dimuat harus ada manfaatnya bagi kehidupan masyarakat. Dengan demikian setiap informasi harus disanir atau dibersihkan dari hal-hal yang dapat merusak sendi-sendi kehidupan masyarakat sebelum menjadi berita.

Sedangkan yang menjadi peranan pers dalam kehidupan masyarakat adalah sebagai agen perubahan (agent of change). Dalam hal ini pers harus mampu mencari, mengumpulkan dan mengolah informasi menjadi berita berdasarkan fakta yang terjadi dalam kehidupan masyarakat. Fakta itu dapat berupa fakta peristiwa seperti hujan turun, longsor dan gunung meletus dan fakta pendapat dapat berupa hasil 
pikiran atau gagasan seseorang mengenai sesuatu, seperti artikel dan tulisan pojok.

Memperhatikan realita sosial yang terjadi dalam kehidupan masyarakat, yang menyangkut kemerdekaan pers ternyata tidak berjalan seiring dengan kehendak UUD 1945. Banyak kasus yang dapat dijumpai dalam pelaksanaan kemerdekaan pers pada masa reformasi yang sungguh-sungguh menciderai dari kehendak negara atas hukum. Adapun antara lain yang menyangkut penyalahgunaan kemerdekaan pers pada orde reformasi adalah Kasus Konflik antara Suku Madura dan Suku Dayak di Kalimantan, Kasus Masalah Agama antara Islam dan Kristen di Ambon, Megawati bau solar, Berita Hoax Ratna Sarumpaet, Kriminalisasi Wartawan, Penyalahgunaan Kode Etik Jurnalistik, Menghukum Orang Melalui Pers dan Wartawan Amplop.

\section{B. RUMUSAN MASALAH}

Berdasarkan latar belakang yang telah diuraikan di atas, maka permasalahan dirumuskan sebagai berikut :

1. Bagaimakah seharusnya konsepsi kemerdekaan pers Indonesia?

2. Apakah pelaksanaan kemerdekaan pers dan pertanggungjawaban hukumnya telah sesuai dengan peraturan perundang-undangan yang berlaku?

\section{PEMBAHASAN}

\section{Konsepsi Kemerdekaan Pers Indonesia}

Kata kemerdekaan (to independence) adalah merupakan konsep yang terikat atau terkait dengan ketatanegaraan suatu negara.

Walaupun Rosseau mengatakan, manusia itu pada hakikatnya mempunyai kebebasan akan tetapi ia punya kebebasan itu terikat dengan norma-norma dan nilai-nilai yang telah terbentuk dalam suatu sistem yang berlaku dalam masyarakat (man is born free, but every where he is chains).

Dengan demikian kemerdekaan pers baik itu melalui media masa cetak maupun melalui media masa elektronik adalah hak asasi manusia yang bersifat fundamental dan lalu berkembang sesuai dengan perkembangan budaya masyarakatnya. Sangat tergantung dengan karakteristik masyarakatnya. Sesuatu yang perlu diperjuangkan dengan memperhatikan kedudukan dan hubungan individu dengan negara, menjadi tugas dan kewajiban untuk mendidik manusia dari manusia yang alami menjadi manusia yang berbudaya.

Aristoteles, seorang ahli pikir Yunani Kuno mengatakan manusia itu adalah Zoon Politicon ${ }^{8}$. Artinya manusia itu hanya dapat hidup layak dan terhormat melalui suatu pergaulan. Sebagai individu tidak akan bahagia hidupnya tanpa manusia lain. Untuk itu manusia membentuk suatu lembaga atau organisasi besar yang bernama negara. Plato juga yang merupakan guru Aristoteles mengatakan bahwa negara itu merupakan organisasi yang dibentuk karena manusia membutuhkannya.

Kemudian Hans Kellsen,
mengatakan bahwa negara
merupakan suatu tertib kaidah
(normnordeming). Dengan demikian
tertib negara (staats orde)
merupakan personifikasi dari tertib


hukum (rechts orde). Hukum mempunyai kekuatan mengikat dalam masyarakat. Oleh karena itu kekuasaan untuk memerintah harus berdasarkan kekuasaan yang terpancar dari hukum dan masyarakat harus mengindahkannya agar tertib negara terjamin. Tertib negara adalah tertib hukum, maka negara identik dengan tertib hukum.

Selanjutnya George Jellineck mengatakan pandangannya melalui Zwei Switen Theorie, bahwa negara dipandang dari segi sosiologis dan yuridis. Dari segi sosiologis negara itu dipandang dari luar, artinya negara adalah gejala masyarakat. Negara merupakan totalitas (als gaizenheid) dan dari segi yuridis dipandang dari dalam, artinya negara sebagai lembaga hukum (als rechtiche institution).

Dalam

Verbanseinheid

Theorie, George Jellineck mengatakan, bahwa dalam negara itu ada dua golongan yaitu ada golongan yang memerintah dan ada golongan yang diperintah. Dengan demikian negara merupakan penjelmaan dari kesatuan perintahperintah untuk mencapai tujuan negara.

Frans Magnis Suseno mengatakan bahwa kebebasan itu dapat dikelompokkan menjadi dua yaitu ; ada kebebasan ekstensial dan kebebasan sosial. Kebebasan ekstensial, berkenaan dengan kemampuan seseorang dengan untuk menentukan tindakan sendiri. Kebebasan itu tidak menekankan segi bebas dari apa akan tetapi bebas untuk apa. Sedangkan kebebasan sosial adalah kebebasan yang harus diterima oleh orang lain dan menekankan bebas dari apa dan atau untuk siapa.

Kemerdekaan pers termasuk kebebasan ekstensial yaitu keleluasaan untuk melakukan aktifitas dan tugas tanpa paksaan dari pihak lain dan kebebasan sosial juga terjadi pada pers ketika pihak ketiga dilarang memaksa pers untuk melakukan atau melaksanakan tindakan-tindakan tertentu. Pemaksaan agar pers melakukan tindakan - tindakan tertentu adalah merupakan perampasan kemerdekaan pers itu sendiri. Jadi jangan seperti Kerbau yang hidungnya dicucuk dan ditarik kesana-kemari oleh si pengembala. Dan sangat tergantung di padang rumput mana Kerbau itu digembalakan.

Oleh karena itu dapat kita menyadari bahwa konsepsi kemerdekaan pers itu sangat terkait dengan sistem demokrasi yang berkembang di negara yang bersangkutan. Jadi kemerdekaan pers Indonesia harus sesuai dengan sistem politik kenegaraan Indonesia yaitu Demokrasi Pancasila. Kita juga harus menyadari warisan nenek moyang, kekeluargaan dan gotong royong sebagai sifat dan watak atau karateristik bangsa Indonesia.

Kemerdekaan pers harus berada dalam koridor Pancasila dan UUD 1945. Wartawan dalam menjalankan tugas dan tanggungjawab jurnalistiknya harus memperhatikan kaidah hukum dan etika yang berlaku di masyarakat. Karena pers dalam negara Pancasila tidak semata-mata mempunyai fungsi bisnis akan tetapi mempunyai fungsi sosial politik. 
2. Pelaksanaan dan Pertanggung jawaban Kemerdekaan Pers Pada Orde Reformasi

Pelaksanaan Kemerdekaan Pers Pada Orde Reformasi

Pers sebagai corong informasi publik. Oleh karena itu pers harus memperjuangkan kebenaran dalam mencari, mengumpulkan dan mengolah informasi itu untuk menjadi sebuah berita. Kebenaran informasi akan terbentuk apabila pers merasakan adanya kemerdekaan dalam mengolah dan membentuk berita berdasarkan fakta, apakah fakta itu peristiwa yang sungguh-sungguh terjadi, seperti tanah longsor dan gempa bumi serta fakta pendapat, hasil pikiran yang berupa seperti artikel dan cerita pendek.

Dalam mengolah dan membentuk sebuah berita, wartawan harus netral atau berimbang dalam memberlakukan narasumber atau subjek berita. Wartawan tidak boleh nakal harus ada kejujuran, profesional dan bertanggungjawab terhadap isi berita. Karena masyarakat ingin mendapatkan berita yang berdasarkan fakta, akurat, benar, jujur dan terpercaya. Karena itu adalah hak asasi manusia yang bersifat fundamental dan dijamin serta mendapatkan perlindungan dari UUD 1945. Sesuatu yang harus diperjuangkan untuk tegaknya kemerdekaan pers. Upaya perjuangan kemerdekaan pers itu baru menghasilkan buah manis dengan tumbangnya kekuasaan Presiden Soeharto tahun 1998. Tumbangnya kekuasaan Presiden Soeharto itu menyebabkan munculnya orde reformasi yang menginginkan adanya perubahan secara total yang menyangkut kehidupan masyarakat, seperti di bidang politik, ekonomi dan termasuk hukum pers.

Kata reformasi berarti adanya kehendak untuk melakukan suatu perubahan dari tatanan selama kepada tatanan atau sistem baru. Berarti juga adanya perubahan pradigma otoriter orde baru dengan semboyan tanggungjawab pers terhadap publik berubah mantranya pada orde reformasi menjadi tanggungjawab publik terhadap pers. Tolak ukur layak atau tidaknya suatu media dibeli dan dibaca sangat tergantung publik.

Pada orde reformasi insan pers benar-benar bernapas lega. Karena terbebas dari belenggu Pemerintahan Orde Baru, dimana pers pada waktu itu banyak yang tiarap atau jadi penakut. Mereka tidak berani bersuara lantang terhadap ketidakadilan akibat adanya ulah oknum penguasa. Ada kekhawatiran juga isi pemberitaan tidak sesuai dengan kehendak penguasa takut marah atau menerima vonis pemberedelan atau pencabutan surat izin usaha penerbitan pers (SIUPP).

Namun merebaknya romantika kemerdekaan pers pada zaman orde ferormasi, ternyata menimbulkan banyak masalah. Terutama dengan hadirnya reformasi dikanca politik dan hukum, insan pers merasa terbebas dari ancaman pemberedelan atau pencabutan izin. Wartawan tidak merasa medianya akan ditutup, apabila melakukan otokritik terhadap pemerintah.

Keadaan itu menjadi penyebab pers tidak terkontrol, eforia kemerdekaan cenderung terjadi 
penyalahgunaan kemerdekaan pers. Kemerdekaan menyatakan pikiran dan atau perasaan sudah berubah arah dari tindakan yang berdasarkan hukum kearah tindakan pelanggaran hukum, seperti penyiaran kabar bohong kasus SARA, fitnah, kriminalisasi terhadap wartawan dan tindakan menghukum orang melalui pers.

Oleh karena itu bahwa kemerdekaan pers pada masa orde reformasi telah keluar dari koridor hukum alias wartawan sering muncul tanpa berita (Muntaber). Wartawan menjadi tukang kompor atau propokator dan adanya konflik bernuansa SARA sehingga menimbulkan pertumpahan darah. Sebagai contoh konflik etnis antara Suku Madura dan Suku Dayak di Kalimantan. Pemberitaan begitu fulgar, sehingga menyebabkan terjadinya konflik. Demikian juga kasus agama di Ambon pers bukan menyejukkan suasana akan tetapi menjadi propokator sehingga menyebabkan terjadinya konflik. Hal lainnya ialah adanya tulisan tentang mulut Mega bau solar, Mega lebih kejam dari Sumanto dan Mega lebih kejam dari lintah darat. Tulisan itu dapat dikategorikan sebagai perbuatan nyerang kehormatan atau martabat Presiden, sehingga Supratman sebagai wartawan tempo terbukti melakukan pelanggaran terhadap Pasal 134 jo Pasal 65 ayat 1 KUHP sebagai dakwaan primer dan pasal 137 jo pasal 65 ayat 1 KUHP sebagai dakwaan subsider. Supratman dijatuhi hukuman percobaan 5 bulan penjara. Artinya si terdakwa tidak menjalani hukuman dengan ketentuan tidak melakukan tindak pidana baru selama dalam tempo masa percobaan.

Demikian juga kasus Ratna Sarumpaet yang telah diduga melakukan penyiaran kabar bohong (hoax) dan terbukti melakukan pelanggaran terhadap pasal 14 ayat 1 UU No. 1 Tahun 1946 dan pasal 28 ayat 2 UU No. 11 Tahun 2008 tentang Undang-Undang informasi transaksi dan elektronik. Dan dihukum penjara 2 tahun di Pengadilan Negeri dan sekarang perkaranya dalam tingkat banding, karena Ratna Sarumpaet termasuk Jaksa Penuntut Umum tidak puas dengan keputusan Hakim Pengadilan Negeri. Hal yang paling fenomenal adalah kasus Pilpres 2019, wartawan seolah-olah tiarap terhadap tragedi meninggalnya para petugas PTS kurang lebih 500 orang. Wartawan takut untuk membuka tabir tragedi itu. Padahal masyarakat sebagai pembaca atau pemerhati perkembangan keadaan masyarakat, punya hasrat besar untuk mengetahui sebab terjadinya tragedinya itu. Apakah peristiwa itu wajar atau tidak wajar, apakah hukum itu tidak bisa menjangkau peristiwa hukum tragedi itu dan apakah hukum juga telah bersujud sama kekuasaan.

Mengenai sistem pertanggungjawaban dalam bidang pers, menurut hukum positif Indonesia ada dua hal yang harus di pertanggung jawabkan dalam pelaksanaan kemerdekaan pers; yang pertama pertanggungjawaban dari segi pidana (code of publication) dan yang kedua dari segi hukum perdata menyangkut perusahaan penerbitan pers (code of enterprice). 
Pertanggungjawaban dari segi hukum pidana menyangkut isi redaksional. Persoalan yang terkait dengan fakta peristiwa maupun fakta pendapat, seperti berita bohong, propokator, ujaran kebencian dan menghukum orang melalui pers (trial by the pers). Isi redaksional itu adalah segala tulisan yang tidak bernilai advertensi, sebagai contoh adanya karikatur Presiden dibuat duduk di kursi, akan tetapi matanya buta dan meraba-raba sesuatu yang ada di sekitarnya dan termasuk kategori penghinaan melalui tulisan.

Secara teoritis dikenal ada tiga persoalan yang menyangkut isi redaksional itu, yang pertama pertanggungjawaban fiktif. Dalam hal ini tidak semata-mata berdasarkan ketentuan KUHP akan tetapi juga berdasarkan UU Pokok Pers. Cukup satu orang yang bertanggungjawab dan yang lainnya bebas dari tanggungjawab hukum. Sebagai contoh pemimpin redaksi yang bertanggungjawab maka yang lainnya bebas dari tanggungjawab (single responsibility).

Kemudian yang kedua adalah pertanggungjawaban reel artinya siapa saja yang terlibat dalam tindak pidana itu harus bertanggungjawab. Mengenai berat ringannya hukuman sangat tergantung pada peranan masing-masing dalam tindak pidana itu. Sebagai contoh kasus penyiaran kabar bohong (hoax) Ratna Sarumpaet, jika itu pelakunya tidak tunggal ada yang turut melakukan dan/atau membantu melakukan maka dapat diancam misalnya pasal 55 KUHP dan pasal 14 ayat 1 UU No. 1 Tahun 1946 dan pasal 28 ayat 1 UU No. 11 Tahun 2008 tentang Informasi, Transaksi dan Elektronik.
Selanjutnya yang ketiga adalah pertanggungjawaban suksesit. Model pertanggung jawaban ini terjadi dengan mengalihkan atau mengindahkan tanggungjawab, sebagai contoh pemimpin redaksi mengalihkan tanggungjawab hukumnya kepada penulis. Ini dapat terjadi apabila ada foto atau nama penulis di dalam suatu artikel.

\section{D.PENUTUP}

\section{KESIMPULAN}

Dari hasil pembahasan dapat diambil kesimpulan sebagai berikut :

1. Konsepsi kemerdekaan pers harus sesuai dengan sistem politik demokrasi yang berkembang, di negara Indonesia yaitu Demokrasi Pancasila. Ini merupakan karakteristik atau nilai-nilai budaya yang telah berurat berakar hidup dalam negara kita sebagai warisan nenek moyang.

2. Pelaksanaan kemerdekaan pers pada orde reformasi tetap bersumber pada pasal 28 UUD 1945. Sistem politik demokrasi dan peraturan perundangundangan pelaksanaannya sangat tergantung kepada penguasa negara, pada awal orde reformasi pers seolah-olah otoriter, tetapi saat ini ada kesan pers mulai tiarap alias takut untuk menyuarakan pendapat atau perasaannya melalui media pers juga ada kesan pers sebagai corong partai politik atau penguasa.

3. Pertanggungjawaban dalam bidang pers bisa dari segi pidana. Jika itu menyangkut isi redaksional. Kalau itu menyangkut segi keperdataan seperti masalah pengangkatan dan pemberhentian karyawan pers, penggajian, jual beli berita dan 
Kemerdekaan Pers Pada Orde Reformasi

asuransi itu menjadi tanggungjawab pemimpin umum perusahaan pers.

\section{SARAN}

Perlu dibentuk lembaga quasi peradilan di bidang pers dupaya tercipta pers yang sehat dan bertanggungjawab yaitu panitia penyelesaian perselisihan pers (P4P).

\section{DAFTAR PUSTAKA}

Amanwinata, Rukmana, 1988. Kemerdekaan Mengeluarkan Pikiran Dengan Tulisan Dalam Pasal 28 UUD 1945, Pasca Sarjana Universitas Padjajaran: Bandung.

Ismail, Taufik, 1987. Sejarah Komunkasi Indonesia, Gramedia: Jakarta.

Loeqman, Lobby, 2003. Malpraktek Pers Indonesia, Asosiasi Wartawan Muslim (AWAM) Indonesia: Jakarta.

Muis, A, 1999. Jurnalistik Hukum Komunikasi Masa, PT. Dharu Anuttama, Jakarta.

Muis, A, 2001. Indonesia Di Era Dunia Maya, PT. Remaja Rosdakarya, Bandung

Nazaruddin, 1988. Diktat Kuliah Hukum dan Komunikasi, IISIP: Jakarta.

Rahmadi F, 1990. Perbandingan Sistem Pers, Gramedia: Jakarta.

Shaffat, Indri, 2008. Kebebasan, Tanggung Jawab dan Penyimpangan Pers, Prestasi Pustaka: Jakarta.

Seno Adji, Oemar, 1982. Dalam Tulisan Hamzah Delik-Delik Pers Indonesia, Media Sarana Pers: Jakarta.
Smith, Edward, 1983. Sejarah Pemberedelan Pers di Indonesia, Grafiti Pers: Jakarta.

Tempo, 27 Oktober 2003

Tempo, 2 Oktober 2018 